\title{
Perbandingan Metode Klasifikasi Berita Hoaks Berbahasa Indonesia Berbasis Pembelajaran Mesin
}

\author{
Muhammad Athaillah ${ }^{*}$, Yufis Azhar ${ }^{2}$, Yuda Munarko ${ }^{3}$ \\ 1,2,3 Teknik Informatika/Universitas Muhammadiyah Malang \\ mathaillah27@gmail.com¹, yufis@umm.ac.id²,yuda@umm.ac.id ${ }^{3}$
}

\begin{abstract}
Abstrak
Klasifiaksi berita hoaks merupakan salah satu aplikasi kategorisasi teks. Berita hoaks harus diklasifikasikan karena berita hoaks dapat mempengaruhi tindakan dan pola pikir pembaca. Dalam proses klasifikasi pada penelitian ini menggunakan beberapa tahapan yaitu praproses, ekstraksi fitur, seleksi fitur dan klasifikasi. Penelitian ini bertujuan membandingkan dua algoritma yaitu algoritma Naïve Bayes dan Multinomial Naïve Bayes, manakah dari kedua algoritma tersebut yang lebih efektif dalam mengklasifikasikan berita hoaks. Data yang digunakan dalam penelitian ini berasal dari www.trunbackhoax.id untuk data berita hoaks sebanyak 100 artikel dan data berita non-hoaks berasal dari kompas.com, detik.com berjumlah 100 artikel. Data latih berjumlah 140 artikel dan data uji berjumlah 60 artikel. Hasil perbandingan algoritma Naïve Bayes memiliki nilai F1-score sebesar 0,93 dan nilai F1-score Multinomial Naïve Bayes sebesar 0,92.
\end{abstract}

Kata Kunci: Klasifikasi, Hoaks, Naïve Bayes, Multinomial Naïve Bayes, F1-Score

\begin{abstract}
Abstarct
Classification hoax news is one of text categorizations applications. Hoax news must be classified because the hoax news can influence the reader actions and thinking patterns. Classification process in this reseacrh uses several stages, namely preprocessing, features extraxtion, features selection and classification. This research to compare Naïve Bayes algorithm and Multinomial Naïve Bayes algorithm, which of the two algorithms is more effective on classifying hoax news. The data from this research from turnbackhoax.id as hoax news of 100 articles and non-hoax news from kompas.com, detik.com of 100 articles. Training data 140 articles dan test data 60 articles. The result of the comparison of algorithms Naïve Bayes has an F1-score value of 0,93 and Naïve Bayes has an F1-score value of 0,92.
\end{abstract}

Keywords: Classification, Hoax, Naïve Bayes, Multinomial Naïve Bayes, F1-Score

\section{Pendahulan}

Media informasi di era perkembangan teknologi sudah semakin berkembang. Kemudahan dalam mengakses media informasi meyebabkan bererdarnya berita-berita hoaks melaui media berita daring yang tidak memiliki badan hukum yang jelas. Menurut Kominfo terdapat sekitar 800.000 situs di Indonesia yang terindikasi menyebarkan berita hoaks [1]. Hoaks menurut Kamus Besar Bahasa Indonesia (KKBI) adalah sebuah berita bohong [2]. Untuk mengatasi permasalahan berita hoaks maka digunakan metode klasifikasi [3].

Secara umum metode klasifikasi teks berbasis pembelajaran mesin terdiri dari tahap praproses, ekstraksi fitur, seleksi fitur dan klasifikasi [4][5]. Pada penelitian sebelumnya yang dilakukan oleh Errissya .R melakukkan klasifikasi berita hoaks dan non-hoaks dengan menerapkan algoritma Naïve Bayes menunjukan hasil akurasi teritinggi dengan nilai akurasi 91,36\% dibandingkan algoritma SVM, C4.5 [5]. Penelitian Amelia .R untuk mengklasifikasikan online news dengan menerapkan Multinomial Naïve Bayes menunjukkan hasil akurasi dengan nilai $94,29 \%$ [6].

Berdasarkan penelitian sebelumnya, penelitian ini bertujuan untuk mengetahui algoritma yang lebih efektif dalam mengklasifikasikan berita hoaks melalui perbandingan algoritma Naïve Bayes dan Multinomial Naïve Bayes dengan mengklasifikasikan berita hoaks berbahasa Indonesia. Untuk mengklasifkan berita hoaks dilakukan tahap praproses, ektraksi fitur, seleksi fitur dan klasifikasi [4][5]. 


\section{Metode Penelitian}

Secara umum langkah penelitian ini digambarkan pada Gambar 1. Pada peneltian ini dilakukan pembuatan model klasifikasi dalam beberapa tahapan yaitu praproses, ekstaksi fitur, seleksi fitur, dan klasifikasi.

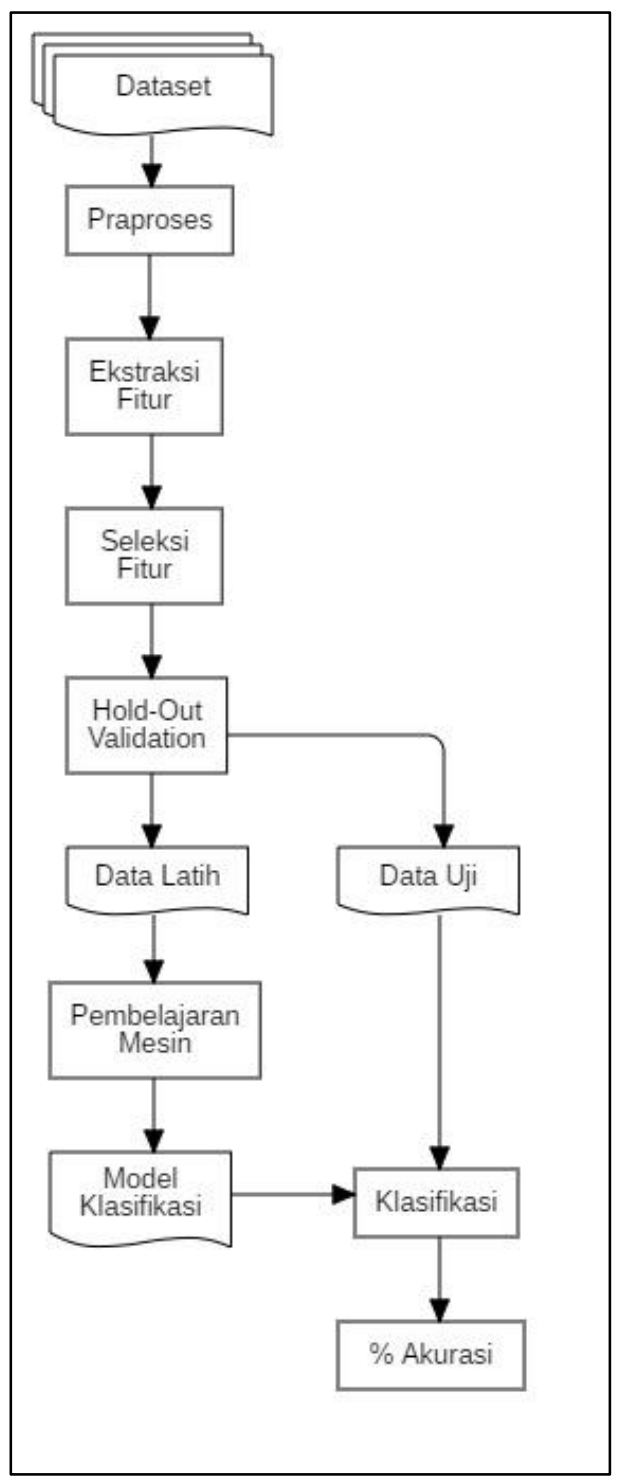

Gambar 1. Alur Peneltian

\subsection{Praproses}

Tahap praproses (prepocessing) merupakan tahap awal yang dilakukan untuk mempersiapkan data agar dapat diolah dengan baik [7]. Pada tahap ini dilakukan untuk menghilangkan noise pada data melaui case folding, tokenizing, stopword removal dan stemming sebagai berikut [5][7].

1. Case Folding adalah proses pengubahan huruf kapital di dalam dokumen menjadi huruf kecil dan menghilangkan karakter selain huruf [7].

2. Tokenizing atau tokenisasi adalah tahapan memecah kalimat yang terdapat dalam dokumen menjadi kata atau frasa [7].

3. Stopword Removal adalah penghapusan kata yang sering muncul dan kata yang tidak memiliki makna [7]. Proses stopword dilakukan dengan menerapkan algpritma NaziefAdriani [8].

4. Stemming adalah proses mengubah kata kembali ke bentuk kada dasarnya sesuai dengan kaidah tata bahasa [7]. Pada proses stemming menerapkan algoritma Nazief-Adriani [8]. 


\subsection{Ekstraksi Fitur}

Ekstraksi fitur adalah proses mengekstrak seluruh fitur kata yang ada di dalam dokumen yang dihasilkan pada sast tokenisasi [5]. Hasil dari proses ini adalah sebagai penciri dari kategori dokumen [5]. Model yang digunakan adalah unigram [5]. Unigram adalah jenis token data pada dokumen yang terdiri dari satu kata [5][9][10].

\subsection{Seleksi Fitur}

Seleksi fitur adalah proses untuk megurangi jumlah fitur untuk meningkatkan proses komputasi saat pembelajaran mesin [5]. Untuk melakukan seleksi fitur digunakan algoritma information gain [5]. Berikut adalah persamaan yang digunakan Persamaan 1 digunakan untuk nilai keseragaman (entropy) keseluruhan data sebelum pemisahan [11][12].

$$
\operatorname{Entropy}(S)=\sum_{i=1}^{k}-(P i) \log _{2}(P i)
$$

Persamaan 2 [12] digunakan untuk keseragaman (entropy) sesudah dilakukan pemisahan (hoaks dan non-hoaks).

$$
\operatorname{Entropy}(S, A)=\sum_{i=1}^{k}\left(\frac{S v}{v} * \operatorname{Entropy}(S v)\right)
$$

Nilai Information gain dihitung dengan Persamaan 3 [12].

$$
\operatorname{Gain}(S, A)=\operatorname{Entorpy}(S)-\operatorname{Entropy}(S, A)
$$

\subsection{Algoritma Klasifikasi}

\subsubsection{Algoritma Naive Bayes}

Naïve Bayes merupakan algoritma klasifikasi yang menggunakan metode probabilistik dan statistik [13]. Algoritma ini memprediksi peluang dimasa depan berdasarkan kejadian yang telah terjadi dimasa lalu [13]. Berikut Persamaan 4 perhutingan Naïve Bayes.

$$
P(C \mid X)=\frac{P(x \mid c) P(c)}{P(x)}
$$

Jika pada kasus tertentu memiliki lebih satu atribut, maka nilai likelihood menggunakan Persamaan 5 [13].

$$
\begin{gathered}
P(x \mid c)=\prod_{j=1}^{n} P(X j \mid C) \\
P(x \mid c)=P\left(X_{1} \mid C\right) P\left(X_{2} \mid C\right) \ldots P\left(X_{j} \mid C\right)
\end{gathered}
$$

Persamaan diatas digunakan untuk proses klasifikasi. Untuk klasifikasi dengan data yang bersifat kontinyu digunakan Persamaan 6 Densitas Gauss [13].

$$
P\left(x_{i} \mid c_{j}\right)=\frac{1}{\sqrt{2 \pi \sigma_{i j}}} e^{-\frac{\left(x_{i}-\mu_{i j}\right)^{2}}{2 \sigma^{2} i j}}
$$
7 [13].

Rumus untuk menghitung rata-rata dari suatu data nilai numerik menggunakan Persamaan

$$
\mu=\frac{\sum_{i=1}^{n} x i}{n}
$$

Rumus untuk menghitung nilai varians Persamaan 8 [13]. 


$$
\sigma^{2}=\frac{\sum_{i=1}^{n}\left(x_{i}-\mu\right)^{2}}{n-1}
$$

\subsubsection{Algoritma Multinomial Naïve Bayes}

Multinomial Naïve Bayes merupakan model proababilistik denhan memperhintungkan frekuensi kemunculan kata pada setiap dokumen kemunculan kata pada setiap dokumen tanpa memperhitungkan urutan kata dan informasi di dalamnya [13], [14]. Berikut Persamaan 9, rumus Multinomial Naïve Bayes sebagai berikut.

$$
P(c \mid d)=P(c) \prod_{1 \leq k \leq n_{d}} P\left(t_{n} \mid c\right)
$$

Probabilitas prior kelas c ditentukkan dengan Persamaan 10 [13].

$$
P(c)=\frac{N_{c}}{N}
$$

Probabilitas kata ke-n menggunakan teknik laplacian smoothing Persamaan 11 [13].

$$
P\left(t_{n} \mid c\right)=\frac{\operatorname{count}\left(t_{n}+1\right)}{\operatorname{count}(c)+|V|}
$$

\subsection{Evaluasi}

Evaluasi digunakan untuk mengukur hasil kinerja dari sistem digumakan confusion matrix. Pengukuran utama adalah akurasi klasifikasi sedangkan precision, recall merupakan untuk mengukur seberapa tepat dan lengkap klasifikasi[15], [16]. Berikut adalah rumus precison, recall dan f1-score.

1. Accuracy nilai adalah perbandingan kasus yang diidentifikasi benar dengan jumlah semua kelas, seperti pada Persamaan 12.

$$
\text { Accuracy }=\frac{T P+T N}{T P+T N+F P+F N}
$$

2. Precision adalah proporsi kasus dengan hasil positif (Persamaan 13).

$$
\text { Precision }=\frac{T P}{T P+F P}
$$

3. Recall adalah proporsi kasus dengan hasil positif diidentifikasi dengan benar (Persamaan 14).

$$
\text { Recall }=\frac{T P}{T P+F N}
$$

4. F1-score adalah perbandingan rata-rata precision dan recall (Persamaan 15).

$$
F 1-\text { score }=2 \times \frac{\text { Recall } \times \text { Precision }}{\text { Recall }+ \text { Precison }}
$$

\section{Hasil Penelitian dan Pembahasan}

Penelitian ini dilakukan dengan menggunakkan data sebanyak 200 artikel berita, terdiri dari 100 berita hoaks dan 100 berita non-hoaks. Proses pelabelan data dilakukan secara manual. Pada proses implementasi diakukan pemisahan data menjadi data latih berjumlah 140 data dan data uji berjumlah 60 data. Dari penelitian ini dihasilkan nilai precision, recall, f1-score berdasarkan hasil klasifikasi algoritma Naïve Bayes dan Multinomial Naïve Bayes sebagai berikut.

REPOSITOR, Vol. 2, No. 5, Mei 2020: 675-682 
1. Naïve Bayes

Dari Gambar 2 dan Gambar 3, Algoritma Naïve Bayes mehgasilkan nilai TP $=29, \mathrm{FP}=1$, $\mathrm{FN}=3, \mathrm{TN}=27$. Sehingga dapat dapat diketahui nilai precision, recall dan $\mathrm{f1}$-score.

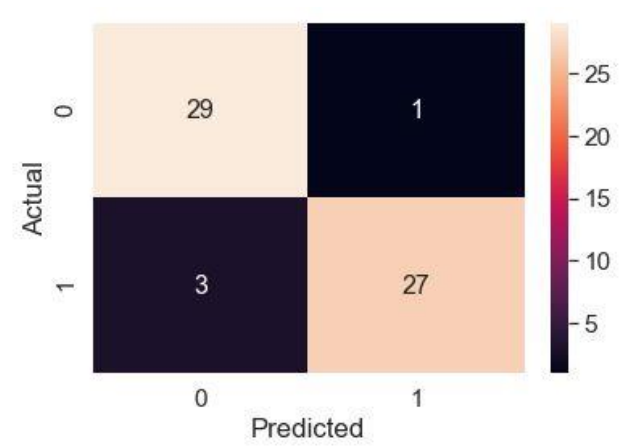

Gambar 2. Confusion Matrix Naïve Bayes

$\begin{array}{rrrrr} & \text { precision } & \text { recall } & \text { f1-score } & \text { support } \\ 0 & 0.91 & 0.97 & 0.94 & 30 \\ 1 & 0.96 & 0.90 & 0.93 & 30 \\ & & & & \\ \text { accuracy } & & & 0.93 & 60 \\ \text { macro avg } & 0.94 & 0.93 & 0.93 & 60 \\ \text { weighted avg } & 0.94 & 0.93 & 0.93 & 60\end{array}$

Gambar 3. Clasification Report Naïve Bayes

2. Multinomial Naïve Bayes

Dari Gambar 4 dan Gambar 5, Algoritma Multinomial Naïve Bayes menghasilkan nilai TP $=27, \mathrm{FP}=3, \mathrm{TN}=2, \mathrm{FN}=28$. Sehingga dapat diketahui nilai precision, recall, dan f1-score.

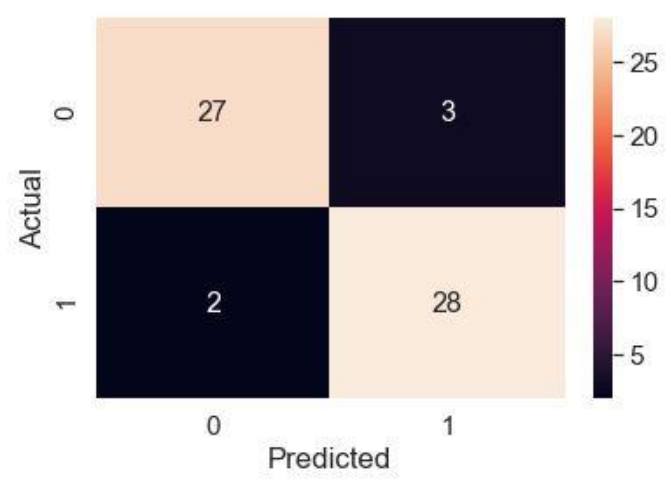

Gambar 4. Confusion Matrix Multinomial Naïve Bayes

$\begin{array}{rrrrr} & \text { precision } & \text { recall } & \text { f1-score } & \text { support } \\ 0 & 0.93 & 0.90 & 0.92 & 30 \\ 1 & 0.90 & 0.93 & 0.92 & 30 \\ & & & & \\ \text { cy } & & & 0.92 & 60 \\ \text { vg } & 0.92 & 0.92 & 0.92 & 60 \\ \text { vg } & 0.92 & 0.92 & 0.92 & 60\end{array}$

Gambar 5. Classification Report Multinomial Naïve Bayes 


\section{Kesimpulan}

Dari hasil penelitian dapat disimpulkan bahwa dalam proses pengklasifikasian berita hoaks berbahasa Indonesia adalah sebagai berikut.

1. Algoritma Naïve Bayes dapat performa lebih dalam mengklasifikasikan dokumen berita hoaks dibandingkan dengan algoritma Multinomial Naïve Bayes.

2. Dari perbandingan algoritma Naïve Bayes dan Multinomial Naïve Bayes berdasarkan hasil akurasi dengan menggunkan perbandingan 140 data latih dan 60 data uji, algoritma Multinomial Naïve Bayes menghasilkan nilai akurasi sebesar 0.92 atau $92 \%$ dan algoritma Naïve Bayes menghasiilkan nilai akurasi sebesar 0.93 atau $93 \%$.

3. Besaran perbandingan data uji dan data latih memiliki pengaruh terhadap nilai akurasi dari kedua algoritma.

\section{Notasi}

The example of notation can be described with the following description:

$\mathrm{Pi} \quad$ : proporsi data $\mathrm{S}$ dengan kelas i

$k \quad$ : jumlah kelas pada output $S$

$v \quad$ : semua nilai yang mungkin dari atribut $A$

Sv $\quad$ : subset $S$ dari atribut $A$ yang $v$

Entropy(S) : nilai entropy sebelum pemisahan

Entropy $(S, A) \quad$ : nilai entropy setelah pemisahan

Gain $(S, A) \quad$ : nilai information gain

$X \quad$ : data kelas yang belum diketahui

$C \quad$ : hipotesis data kelas spesifik

$P(C / X) \quad$ : probabilitas hipotesis berdasarkan kondisi (posteriori)

$P(c) \quad$ : probabilitas hipotesis (prior)

$P(x / c),\left(P\left(t_{n} / c\right)\right.$ : likelihood, yaitu peluang ditemukkannya data $x$ di kelas $c$

$P(x) \quad$ : evidence, yaitu peluang data $x$

$i \quad$ : indeks nilai atribut $X$

$n \quad$ : jumlah atibut pada kasus

$X_{j} \quad$ : nilai atribut ke $X$

$\mu \quad$ : rata-rata populasi

$\pi \quad$ : phi setara 3,14

$\sigma^{2} \quad$ : nilai varians

$e \quad$ : nilai ekpnensial, ekuivalen dengan 2,73183

$\operatorname{count}\left(t_{n}, c\right)$ : jumlah kata $t_{n}$ data pelatihan kategori $\mathrm{C}$

$\operatorname{count}(c) \quad$ : jumlah kata di seluruh data pelatihan $\mathrm{c}$

$V \quad$ : Jumlah seluruh kata pada data pelatihan

\section{Referensi}

[1] Kementrian Komunikasi dan Informatika Republik Indonesia, "Ada 800.000 Situs Penyebar Hoax di Indonesia," 2017. .

[2] Kementerian Pendidikan dan Kebudayaan Republik Indonesia, "KBBI Daring," 2016. .

[3] T. Petković, T. Petković, Z. Kostanjčar, and P. Pale, "E-Mail System for Automatic Hoax Recognition," 2005.

[4] Y. Y. Chen, S.-P. Yong, and A. Ishak, "Email Hoax Detection System Using Levenshtein Distance Method," J. Comput., vol. 9, no. 2, pp. 441-446, 2014.

[5] E. Rasywir and A. Purwarianti, "Eksperimen pada Sistem Klasifikasi Berita Hoax Berbahasa Indonesia Berbasis Pembelajaran Mesin," J. Cybermatika, vol. 3, no. 2, pp. 1-8, 2015.

[6] A. Rahman, "Online News Classification Using Multinomial Naive Bayes," vol. 6, no. 1, 2017.

[7] R. A. Baeza-Yates and B. Ribeiro-Neto, "Modern Information Retrieval," vol. 9, 1999.

[8] M. Adriani, J. Asian, B. Nazief, S. M. M. Tahaghoghi, and H. E. Williams, "Stemming Indonesian: A confix-stripping approach," ACM Trans. Asian Lang. Inf. Process., 2007.

[9] A. Nurfalah and A. Ardiyanti Suryani, "Analisis Sentimen Berbahasa Indonesia Dengan Pendekatan Lexicon-Based Pada Media Sosial,” vol. 2, no. 1, pp. 2541-5093, 2017.

[10] W. C. Indhiarta, "Penggunaan N-Gram Pada Analisa Sentimen," 2017.

[11] " " C.E. Shannon , vol. 27, pp. , July, October, "A Mathematical Theory of Communication," Bell Syst. Tech. J., vol. 27, no. April 1928, pp. 379-423,623-656, 1948. 
[12] J. R. Quinlan, "Induction of Decision Trees," Mach. Learn., 1986.

[13] T. M. Mitchell, (Mcgraw-Hill International Edit) Thomas Mitchell-Machine learning-McGraw Hill Higher Education (1997). 1997.

[14] C. D. Manning, Intro to Information Retrieval. 2009.

[15] A. H. Setianingrum, D. H. Kalokasari, and I. M. Shofi, "Implementasi Algoritma Multinomial Naive Bayes Classifier," J. Tek. Inform., vol. 10, no. 2, pp. 109-118, 2018.

[16] D. D. Lewis and W. A. Gale, "A sequential algorithm for training text classifiers," in Proceedings of the 17th Annual International ACM SIGIR Conference on Research and Development in Information Retrieval, SIGIR 1994, 1994. 
REPOSITOR, Vol. 2, No. 5, Mei 2020: 675-682 